\title{
PREPARATION AND CHARACTERIZATION OF SELF-MICROEMULSIFYING DRUG DELIVERY SYSTEM (SMEDDS) OF CISPLATIN FOR ORAL USE IN OVARIAN CANCER TREATMENT
}

\author{
IRFAN AKARTAS ${ }^{1 *}$ and H. YESIM KARASULU ${ }^{2}$ \\ ${ }^{1}$ Faculty of Pharmacy, European University of Lefke, \\ Lefke, Turkish Republic of Northern Cyprus, TR-10, Mersin, Turkey \\ ${ }^{2}$ Department of Pharmaceutical Technology, Faculty of Pharmacy, \\ Ege University, Bornova, 35040 Izmir, Turkey
}

\begin{abstract}
Cisplatin is an antineoplastic drug, used for the treatment of ovarian cancer. SMEDDS has many advantages such as enhanced bioavailability, lymphatic targeting and ease of manufacture. The main objective of this study was to prepare and characterize Cisplatin loaded SMEDDS formulation and to evaluate antitumoral activity with cell viability studies. Cisplatin SMEDDS formulation was prepared and characterized physicochemically. In vitro release studies and cell viability studies were performed and evaluated. The mean droplet size of Cisplatin SMEDDS was measured as $25.4 \pm 1.9 \mathrm{~nm}$ and PDI was $0.241 \pm 0.018$. Refractive index of the formulation was measured as $1.471 \pm 0.001$. $\mathrm{pH}$ values of Cisplatin SMEDDS (dilution ratio $1: 10$ water) were measured as $5.84 \pm 0.09$ and (dilution ratio $1: 10 \mathrm{pH} 6.8 \mathrm{PBS}$ ) $6.51 \pm 0.14$. The viscosity of formulation was measured as $284 \mathrm{mPa}$. According to in vitro release studies, $78.17 \%$ of Cisplatin was released from Cisplatin SMEDDS. The formulation showed a cytotoxic effect to A2780 cells; vitality were found $20.26 \%$ at $0.02 \mu \mathrm{g} / \mathrm{mL}$. It was concluded that Cisplatin SMEDDS could be beneficial for the treatment of ovarian cancer and it could be a promising alternative due to its enhanced bioavailability.
\end{abstract}

Keywords: Cisplatin, SMEDDS, ovarian cancer, in vitro release, cytotoxicity

Cancer is one of the most leading causes of death in the world. Ovarian cancer is the seventh most common cancer in women. Also, it has the highest, mortality rate among female reproductive system cancers (1). According to the American Cancer Society in 2018, 22240 new cases of ovarian cancer will be diagnosed and 14070 women will die of ovarian cancer in the United States (2). The highest incidences are related in Europe, Canada and the United States. The lowest incidences are reported in China and Africa. According to GLOBOCAN 2008 database, the incidence rates are reported as over 11 cases per 100000 in Europe, less than 3 cases per 100000 in Africa and 4-8 cases per 100000 in South American, Asian and Caribbean countries (3). The latest cancer mortality statistics of the World Health Organization (WHO) showed that mortality will increase by approximately 45\% until 2030 (4).

Ovarian cancer has different risk factors like family history, age, early age menarche, menopause, parity, oral contraceptive use, lactation, obesity, cigarette smoking and alcohol consumption (5-7). Epithelial ovarian cancer is the most common type of ovarian cancer. Early diagnosis increases the chances successful treatment. The pathogenesis of ovarian cancer hasn't been elucidated yet, but ovulation, hormonal factors and inflammations have an important role in it $(8,9)$. There are two types of ovarian tumors. Type I tumors tend to be less aggressive and slow-growing like low grade malign serous tumors, low grade malign endometrioid carcinoma and mucinous carcinoma. Type II tumors are more aggressive than Type I tumors. They are high grade malign serous carcinoma, carcinosarcoma and undifferentiated carcinoma $(10,11)$.

Ovarian cancer is staged by using the FIGO staging system which has 4 stages. A tumor is limited to the ovary at stage I. During stage II, tumor involves one or both of the ovaries. Pelvic extension and primary peritoneal tumor occurred. At stage III,

* Corresponding author: e-mail: iakartas@eul.edu.tr 
the tumor involves one or both of the ovaries like stage II. Tumor or lymph nodes occurred outside of the pelvis. At stage IV, distant metastasis occurred outside of the peritoneum $(12,13)$.

Lipid-based formulations are used to enhance the solubility and bioavailability of drugs which are less soluble in water. These systems have advantages such as high bioavailability, effective drug delivery for lipophilic drugs, enhanced absorption and drug loading capacity, ease of manufacture. Also, these systems have a few disadvantages like toxicity of surfactants and precipitation of drug (14-16).

Lipid-based systems have 4 types. Type I is triglyceride mixtures, Type II is self-emulsifying drug delivery systems which consist of oil and surfactant, Type III is self microemulsifying drug delivery systems which consist of oil, surfactant and co-surfactant, Type IV is micellar mixtures which are surfactant and co-surfactant mixtures (17). In this study, we have formulated a Type III system (SMEDD). SMEDDSs are self emulsified systems that are generally used for oral drug delivery to enhance bioavailability and stability. These systems have $<100 \mathrm{~nm}$ particle size. SMEDDS are thermodynamically stable systems that have numerous advantages like spontaneous microemulsion formation, ease of manufacture, enhanced solubility. SMEDDS shows higher bioavailability when used orally. This means fewer doses of the drug is needed to be used. In fact, these systems minimize side effects and toxicity (18-20).

Cisplatin (cis-diamminedichloroplatinum (II)) is an anticancer drug that is effective in various types of cancers such as testicular, ovarian, bladder and lung cancer. Its mechanism of action is to cause DNA damage as a crosslinker to purine bases, interfering with DNA repair mechanism in cancer cells. However, Cisplatin has side effects such as nephrotoxicity, ototoxicity, neurotoxicity, hematologic and gastrointestinal effects, vascular toxicity and allergic effects (21).

Cisplatin has metallic platinum, two ammines and two chloride groups which are structured in Figure 1. It is a yellow crystalline powder at room temperature, has a melting point of $270^{\circ} \mathrm{C}$. Cisplatin

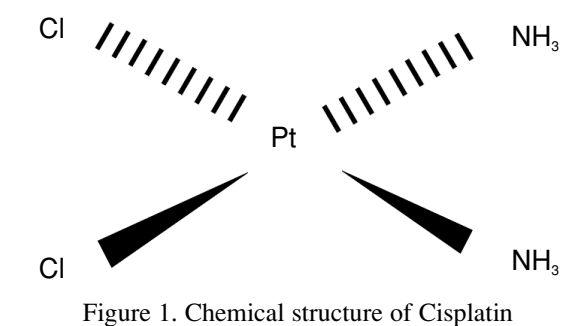

is slightly soluble in water $(0.253 \mathrm{~g} / 100 \mathrm{~g})$ and insoluble in ethanol. Its Log P-value is -2.19 (22, 23). Cisplatin is used as injection form with 50 $\mathrm{mg} / \mathrm{mL} ; 100 \mathrm{mg} / \mathrm{mL}$ (FDA). Cisplatin has also an oral form "CP Ethypharm" which is in Phase I clinical trials (24).

To sum up briefly, SMEDDS of Cisplatin leads to an expectation for ovarian cancer treatment because of enhanced solubility, bioavailability and lymphatic targeting. One of the major advantages of using the lymphatic system is the avoidance of firstpass metabolism and enhancing the bioavailability of drugs (25). Although SMEDDSs have some limitations such as precipitation of drug on dilution, encapsulation in soft gelatin capsules, storage, oxidation of lipids in SMEDDS formulation; they have important advantages such as ease of storage, improved physical and chemical stability, ability to promote rapid oral absorption of drug, not being affected by food, ease of manufacture and scale-up (26). Also, Cisplatin SMEDDS has many advantages such as ease of application, self-administration, non-painful and low-cost of production processes due to its oral use when compared with parenteral application (27). The aim of the study is to prepare self microemulsifying drug delivery system of Cisplatin and enhance the lymphatic permeation of drug. Taking into account for this aim; characterization, in vitro release, cell viability and cytotoxicity studies were evaluated.

\section{EXPERIMENTAL}

\section{Materials}

Cisplatin (cis-diamminedichloroplatinum (II)) was purchased from Sigma Aldrich, Germany. Isopropyl myristate (IPM) was purchased from Merck, Germany. Kolliphor EL and Propylene glycol were purchased from Sigma Aldrich, Germany. Dialysis membrane (14000 Da) was purchased from Spectra Por, USA. A2780 cell line was purchased from American Type Culture Collection (ATCC), USA. RPMI 1640 and Fetal bovine serum (FBS) were purchased from Biological Industries, USA. MTT (3-(4,5-dimethylthiazol-2-yl)-2,5-diphenyltetrazolium bromide) were purchased from Merck, Germany. All of the other chemicals and solvents were analytical grade.

\section{Preparation of SMEDDS formulations}

Firstly, pseudoternary phase diagrams were constructed by using water titration method in order to determine the stable microemulsion range. During the formulation development studies, surfac- 
tant and cosurfactant were mixed with different ratios. Surfactant:cosurfactant $(\mathrm{w} / \mathrm{w})$ mixed with the ratios $1: 1,1.25: 1$ and $1.5: 1$ to form three different formulations. Oil, surfactant and cosurfactant were mixed in a beaker with $50 \mathrm{rpm}$ speed and titrated with water at $25^{\circ} \mathrm{C}$ (28). Microemulsions were determined visually until the formation of turbidity. Pseudo-ternary phase diagrams were constructed by using a software program that was developed by using Microsoft Visual Basic. With this software program, the percentage values of water, oil and surfactant/cosurfactant in microemulsion are entered and the pseudoternary phase diagram is obtained automatically (29).

Microemulsions were prepared in consideration of pseudoternary phase diagrams. With the help of the pseudoternary phase diagram, the ratio of surfactant to co-surfactant was optimized. Then, by varying the ratio of oil to the optimized ratio of surfactant to co-surfactant, different formulations were prepared without the drug. Isopropyl myristate was used as the oil phase, Kolliphor EL was used as surfactant and Propylene glycol was used as cosurfactant. $0.11 \mathrm{~mL}$ Isopropyl myristate was added to the mixture of 0.4 $\mathrm{mL}$ Kolliphor EL and $0.49 \mathrm{~mL}$ Propylene glycol $(1.62: 1)$, then these formulations were vortexed for 5-10 minutes with a vortex shaker until a clear solution was obtained. After the equilibrium of microemulsions, $2 \mathrm{mg}$ Cisplatin was added and dissolved in this mixture. The concentration of microemulsions was $2 \mathrm{mg} / \mathrm{mL}$ which is the solubility of Cisplatin in this microemulsion $(30,31)$.

\section{Characterization of SMEDDS formulation}

The physicochemical properties of microemulsions such as physical appearance, $\mathrm{pH}$, refractive index, viscosity, droplet size, polydispersity index (PDI), zeta potential, dispersion stability were measured in order to evaluate characteristic properties of microemulsion $(31,32)$.

Physical appearance was found clear on visual inspection. $\mathrm{pH}$ was measured with $\mathrm{pH}$-meter (Mettler Toledo, Germany). The refractive index was measured with a digital refractometer (Atago RX-7000, Japan). Viscosity was measured with Brookfield DVII+ Pro (A\&D Company, Japan) viscometer using Ula spindle. Droplet size, PDI and zeta potential was measured with Malvern NanoZS, UK. Measurements were performed at $25 \pm 2^{\circ} \mathrm{C}$, mean and standard deviation values were calculated $(n=3)$.

\section{In vitro release studies of Cisplatin SMEDDS}

In order to provide lymphatic targeting of Cisplatin SMEDDS, the formulation should be tar- geted to the intestine. For this aim, enteric coating of Cisplatin SMEDDS should be performed and 2 $\mathrm{mg} / \mathrm{mL}$ dosed capsules will be obtained. Due to that reason, in vitro release medium was prepared as 0.1 $\mathrm{N}$ pH 6,8 phosphate buffer solution in order to simulate intestinal fluid. It was ensured that Cisplatin SMEDDS filled enteric-coated capsules keep their integrity for $2 \mathrm{~h}$ in $600 \mathrm{~mL} 0.1 \mathrm{~N} \mathrm{pH} 1.2 \mathrm{HCl}$ buffer solution (USP XXII-buffer solutions) at $37 \pm 0.1^{\circ} \mathrm{C}$ $50 \mathrm{rpm}$ during in vitro release tests. $2 \mathrm{mg} / \mathrm{mL}$ concentration of Cisplatin loaded SMEDDS was prepared and $1 \mathrm{~mL}$ of this formulation was filled into Spectra Por/diameter 16 mm/ MW 14000 Da dialysis membrane by automatic pipette. The membrane was blocked with 2 weighted clamps from up and down position to sink the membrane. In vitro release studies were performed with magnetic stirrer in $600 \mathrm{~mL}$ of $0.1 \mathrm{~N} \mathrm{pH} 6.8$ phosphate buffer solution (USP XXII-buffer solutions) at $37 \pm 0.1^{\circ} \mathrm{C}$ $50 \mathrm{rpm}$. Samples were collected at significant times $(0,5,15,30,45,60,90,120,150,180,210,240$ minutes) and analyzed with a validated HighPerformance Liquid Chromatography (HPLC) method (Shimadzu, Japan) at $254 \mathrm{~nm}$ which was validated according to ICH validation guidelines. Linearity, range, precision, accuracy, specificity, and sensitivity studies were performed. The retention time was detected as 9.27 minutes, peak purity was 1. HPLC method was validated according to ICH validation guidelines; linearity, range, precision, accuracy, specificity, and sensitivity studies were performed. The obtained results were found to be in accordance with the acceptance criteria (33). Six points calibration curve was drawn with the range of $0.1-10 \mu \mathrm{g} / \mathrm{mL}$ for the standard solution of Cisplatin. The equation of regression line is $\mathrm{y}=$ $74387 \mathrm{x}-8076,1$ and regression coefficient $\left(\mathrm{R}^{2}\right)$ of the line is 0.9993. Limit of detection (LOD) and limit of quantification (LOQ) values were calculated as 0.09 and $0.29 \mu \mathrm{g} / \mathrm{mL}$ respectively. Results were evaluated in considering the calibration curve of Cisplatin in 0,1 N pH 6,8 phosphate buffer medium. Measurements were performed, mean and standard deviation values were calculated $(n=3)$. Sink conditions were ensured during the studies. The results of the study were evaluated by kinetic parameters (Zero-order release, First order release, Higuchi model, Hixson-Crowel model, Langenbucher model) with a software program that was developed by using Microsoft Visual Basic. With this software program, the percentage values of released Cisplatin vs. time are entered and the kinetic model of drug release is detected according to the coefficient of determination $\left(r^{2}\right)$ values $(34,35)$. 


\section{Cell viability and cytotoxicity studies of Cisplatin SMEDDS}

The effect of Cisplatin SMEDDS formulation was determined by MTT assay on A2780 cell line. A2780 cell line is a human ovarian carcinomic cell line that is procured by the European Collection of Cell Cultures (ECACC).

To evaluate the activity and cytotoxicity of Cisplatin SMEDDS formulation on A2780 cell line, $1 \times 10^{4}$ cells $/ \mathrm{mL}$ concentration of A2780 cell medium was seeded $100 \mu \mathrm{L}$ in 96 -well culture plates. Cells were incubated at incubator with conditions of $37^{\circ} \mathrm{C}, 95 \%$ air- $5 \% \mathrm{CO}_{2}$. After $24 \mathrm{~h}$, the medium was removed and cytotoxicity studies were started. Cisplatin solution, blank SMEDDS and Cisplatin SMEDDS were diluted with RPMI-1640 medium supplemented with $10 \%$ fetal bovine serum (FBS), $100 \mathrm{unit} / \mathrm{mL}$ penicillin, $100 \mu \mathrm{g} / \mathrm{mL}$ streptomycin and $2 \mathrm{mM}$ L-Glutamine. Cisplatin solution, blank SMEDDS and Cisplatin SMEDDS was prepared with different concentration of samples $(0.02,0.2,2$, $20 \mu \mathrm{g} / \mathrm{mL}$ ). Different concentrations of sample mediums were incubated for 24 and $48 \mathrm{~h}$. After that, sample mediums were removed and cells were incubated for $4 \mathrm{~h}$ with $100 \mu \mathrm{L}$ of 3-(4,5-dimethyl-2-thiazolyl)-2,5-diphenyl-2H-tetrazolium bromide (MTT) taken from $5 \mathrm{mg} / \mathrm{mL}$ of MTT/PBS stock solution. After incubation, the medium was removed and 100 $\mu \mathrm{L}$ of DMSO was added to each well. Cell viability was evaluated with ELISA microplate reader-UV spectrophotometer (Thermo vario scan-FHA multiplate reader) at $570 \mathrm{~nm}$. Measurements were performed, mean and standard deviation values were calculated $(n=3)$. $(36,37)$.

\section{RESULTS AND DISCUSSION}

\section{Preparation of SMEDDS formulations of Cis- platin}

First of all, IPM was selected as oil phase, Kolliphor EL was selected as a surfactant, Propylene Glycol was selected as co-surfactant to prepare SMEDDS. These components were selected after the solubility studies of Cisplatin. IPM, known

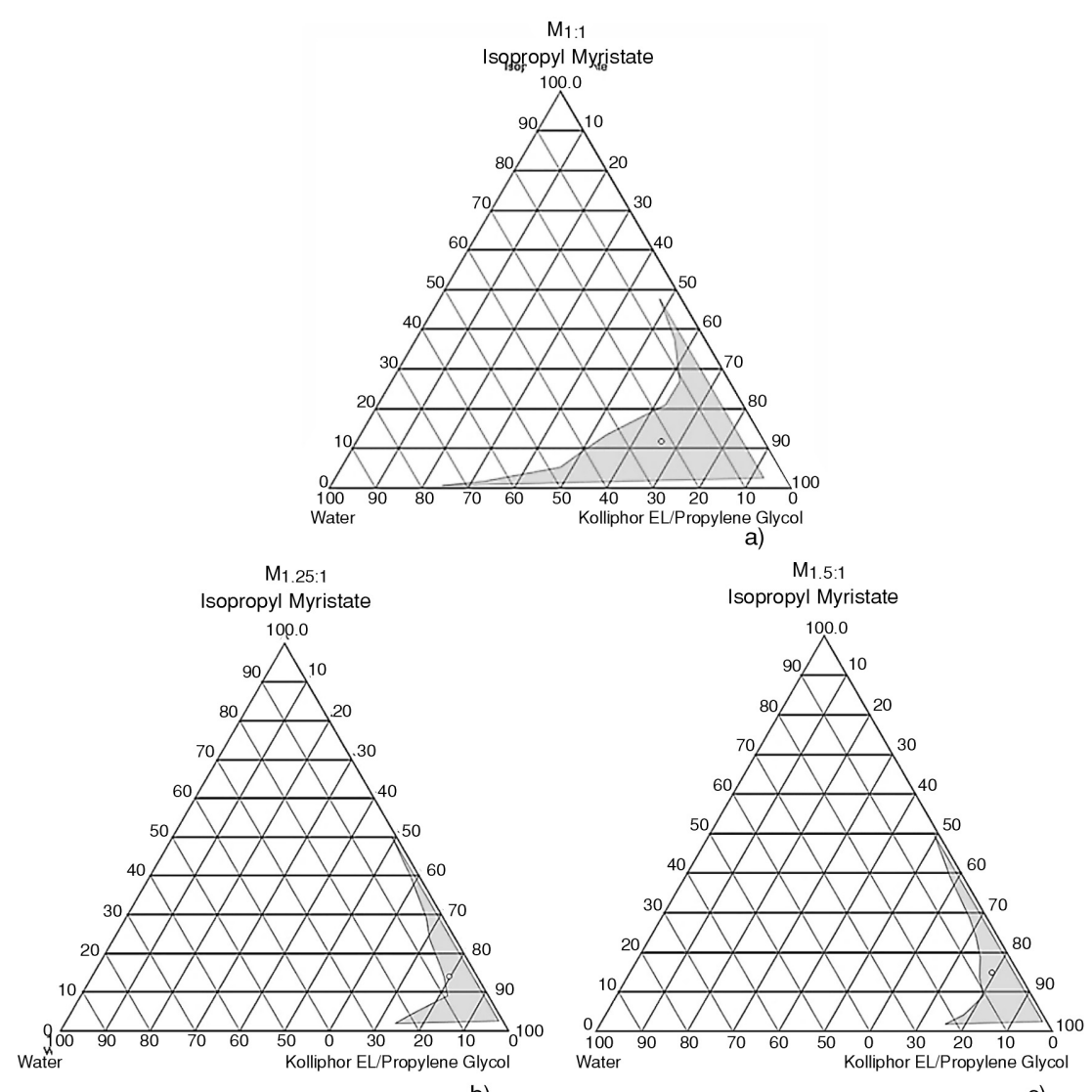

b)

Figure 2. Pseudo-ternary phase diagrams of $\mathrm{M}_{1: 1}$ (a), $\mathrm{M}_{1.25: 1}$ (b) and $\mathrm{M}_{1.5: 1}$ (c) microemulsion formulations with the components of IPM, Kolliphor EL, Propylene Glycol and water. 
Table 1. Concentration ratio of the components of $\mathrm{M}_{1: 1}$ microemulsion formulation.

\begin{tabular}{|c|c|c|c|}
\hline IPM \% & Kolliphor EL \% & Propylene glycol \% & Water \% \\
\hline 0.627 & 12.045 & 12.045 & 65.282 \\
\hline 1.730 & 16.263 & 16.263 & 47.368 \\
\hline 5.263 & 23.684 & 23.684 & 41.420 \\
\hline 8.876 & 24.852 & 24.852 & 33.333 \\
\hline 13.333 & 26.666 & 26.666 & 16.807 \\
\hline 21.008 & 31.092 & 31.092 & 10.714 \\
\hline 26.786 & 31.250 & 31.250 & 6.542 \\
\hline 37.383 & 28.037 & 28.037 & 4.762 \\
\hline 47.619 & 23.810 & 23.810 & \\
\hline
\end{tabular}

Table 2. Concentration ratio of the components of $\mathrm{M}_{1.25: 1}$ microemulsion formulation.

\begin{tabular}{|c|c|c|c|}
\hline IPM \% & Kolliphor EL \% & Propylene glycol \% & Water \% \\
\hline 1.901 & 41.065 & 32.699 & 24.335 \\
\hline 4.032 & 41.935 & 33.871 & 9.091 \\
\hline 9.091 & 45.454 & 36.364 & 7.407 \\
\hline 13.888 & 43.518 & 35.185 & 6.604 \\
\hline 18.868 & 41.509 & 33.019 & 5.714 \\
\hline 23.809 & 39.048 & 31.4289 & 3.883 \\
\hline 29.126 & 37.864 & 29.126 & 1.980 \\
\hline 39.604 & 32.673 & 25.742 & 1 \\
\hline 50 & 27 & 22 & \\
\hline
\end{tabular}

Table 3. Concentration ratio of the components of $\mathrm{M}_{1.5: 1}$ microemulsion formulation.

\begin{tabular}{|c|c|c|c|}
\hline IPM \% & Kolliphor EL \% & Propylene glycol \% & Water \% \\
\hline 1.945 & 45.136 & 30.351 & 17.355 \\
\hline 4.133 & 47.107 & 31.405 & 10.714 \\
\hline 8.928 & 48.215 & 32.143 & 9.091 \\
\hline 13.636 & 46.364 & 30.909 & 6.542 \\
\hline 18.691 & 44.860 & 29.907 & 4.762 \\
\hline 23.810 & 42.857 & 28.571 & 3.846 \\
\hline 28.846 & 40.385 & 26.923 & 2.913 \\
\hline 38.835 & 34.951 & 23.301 & 0.991 \\
\hline 49.505 & 29.703 & 19.802 & \\
\hline
\end{tabular}

as polar emollient, is the ester of isopropyl alcohol and myristic acid. The high amount of surfactant and co-surfactant is necessary to draw pseudo-ternary phase diagrams and determine the microemulsion region (38). Kolliphor EL, formerly known as Cremophor EL, is a non-ionic surfactant and emulsifier for the production of semi-solid and liquid for- mulations. It demonstrates good compatibility with other ingredients and can be used with essential oils (39). Also, non-ionic surfactants are less toxic than ionic surfactants. As the A2780 cell lines are sensitive to toxic materials, it is an advantage for the cytotoxicity studies. Propylene glycol, an organic compound, is hygroscopic and miscible with water. This 
is an advantage to develop a stable SMEDDS formulation which has no phase separation. Propylene glycol is used as a solvent for oral pharmaceutical preparations and it is generally known as safe (40).

In order to determine the optimum concentration range of components and prepare microemulsion, pseudo-ternary phase diagrams were constructed by using a software program. After the construction of pseudo-ternary phase diagram, the concentration range of components can easily be obtained in the microemulsion area. The gravity center of pseudo-ternary phase diagrams provides finding out the optimum ratio of the components to prepare microemulsion. Concentration ratio of the components was given in Table 1-3. The pseudo-ternary phase diagrams of blank microemulsions (without Cisplatin) with different surfactant:co-surfactant (S:Co-S) ratios were shown in Figure 2. The area of $\mathbf{M}_{1: 1}$ (surfactant:co-surfactant is $1: 1$ ), $\mathbf{M}_{1.25: 1}$ (surfactant:co-surfactant is $1.25: 1$ ) and $\mathrm{M}_{1.5: 1}$ (surfactant:co-surfactant is $1.5: 1)$ microemulsion regions were calculated as $639.89,210.52$ and 215.94 respectively. According to the results of the area, $\mathrm{M}_{1: 1}$ has the highest microemulsion area. With considering the pseudo-ternary phase diagram of $\mathrm{M}_{1: 1}$, SMEDDS formulation was developed with IPM, Kolliphor EL and Propylene Glycol. The ratio of Kolliphor EL was decreased and the ratio of Propylene Glycol was increased due to the toxicity of surfactant to A2780 cells.

$0.11 \mathrm{~mL}$ IPM, 0,4 mL Kolliphor EL and 0.49 $\mathrm{mL}$ Propylene Glycol was mixed to form $1 \mathrm{~mL}$ of SMEDDS formulation. After that, $2 \mathrm{mg}$ of Cisplatin was added and dissolved in this formulation.

In a study by Omari-Siaw et al. perillaldehydeloaded SNEDDS was developed with constructing pseudo-ternary phase diagrams. These diagrams were drawn with different oil phases such as IPM, medium-chain triglyceride and perillaldehyde. Kolliphor
EL was selected as a surfactant and PEG 200 was selected as co-surfactant. It was stated that the wider shaded region of the diagram, has the better selfnanoemulsification ability and the formulation system consisting of Kolliphor EL and PEG 200 with PAH-IPM/MCT mixture (1: 1) was recorded as the largest shaded area among these diagrams. The final system consisting PAH-IPM/MCT mixture (1: 1) (40\% w/w), Kolliphor EL (48\% w/w) and PEG 200 $(12 \% \mathrm{w} / \mathrm{w})$ was formulated. In our system, IPM $(11 \%$ w/w), Kolliphor EL (40\% w/w) and Propylene Glycol $(49 \% \mathrm{w} / \mathrm{w})$ were used to develop formulation (41).

In a study of Wang et al. pseudo ternary phase diagrams were constructed by using water titration method which is the same method of our study to detect the microemulsion region. From the solubility of trans-cinnamic acid, medium-chain triglyceride and IPM were found superior for the oil phase of SNEDDS, Kolliphor EL was selected as a surfactant and PEG 400 was selected as co-surfactant (42).

\section{Characterization of SMEDDS formulation}

Physical appearance, $\mathrm{pH}$, refractive index, viscosity, droplet size, PDI, zeta potential, distribution stability were measured in order to characterize the microemulsion. The droplet size of Cisplatin loaded SMEDDS was measured as $25.4 \pm 1.9 \mathrm{~nm}$, PDI was determined as $0.241 \pm 0.018$. The droplet size of Cisplatin loaded SMEDDS which was diluted with the ratio of $1: 10$ by water (dilution ratio $1: 10$ water) was measured as $44.8 \pm 1.8 \mathrm{~nm}$, and PDI was determined as $0.276 \pm 0.013$. The droplet size of Cisplatin loaded SMEDDS which was diluted with the ratio of $1: 10$ by $0.1 \mathrm{~N} \mathrm{pH} 6.8$ phosphate buffer solution (dilution ratio $1: 10 \mathrm{pH} 6.8 \mathrm{PBS}$ ) was measured as $79.1 \pm 0.8 \mathrm{~nm}$, and PDI was determined as $0.312 \pm 0.002$. After $24 \mathrm{~h}$, measurements were performed again. The different droplet sizes of the diluted microemulsions with different mediums can

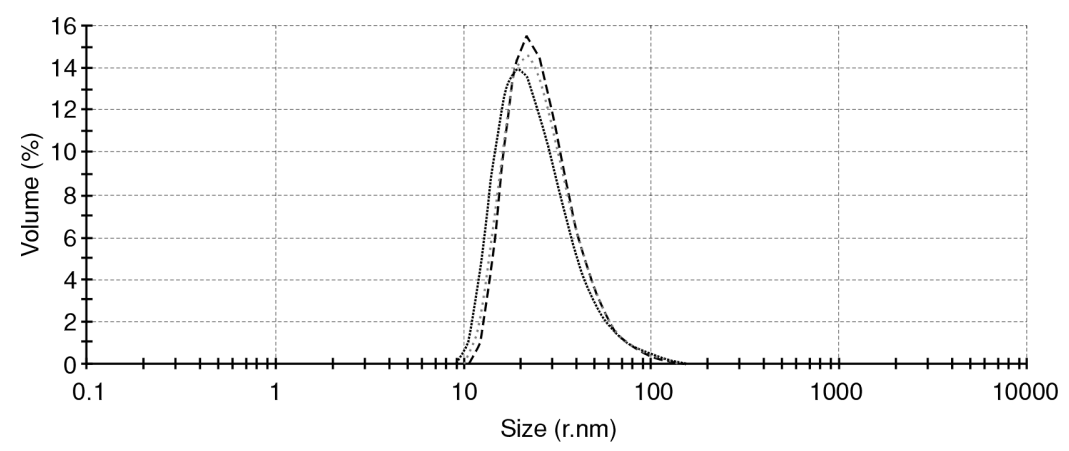

Figure 3. The droplet size distribution of Cisplatin SMEDDS (diluted with $1: 10$ water in 0 hour). 


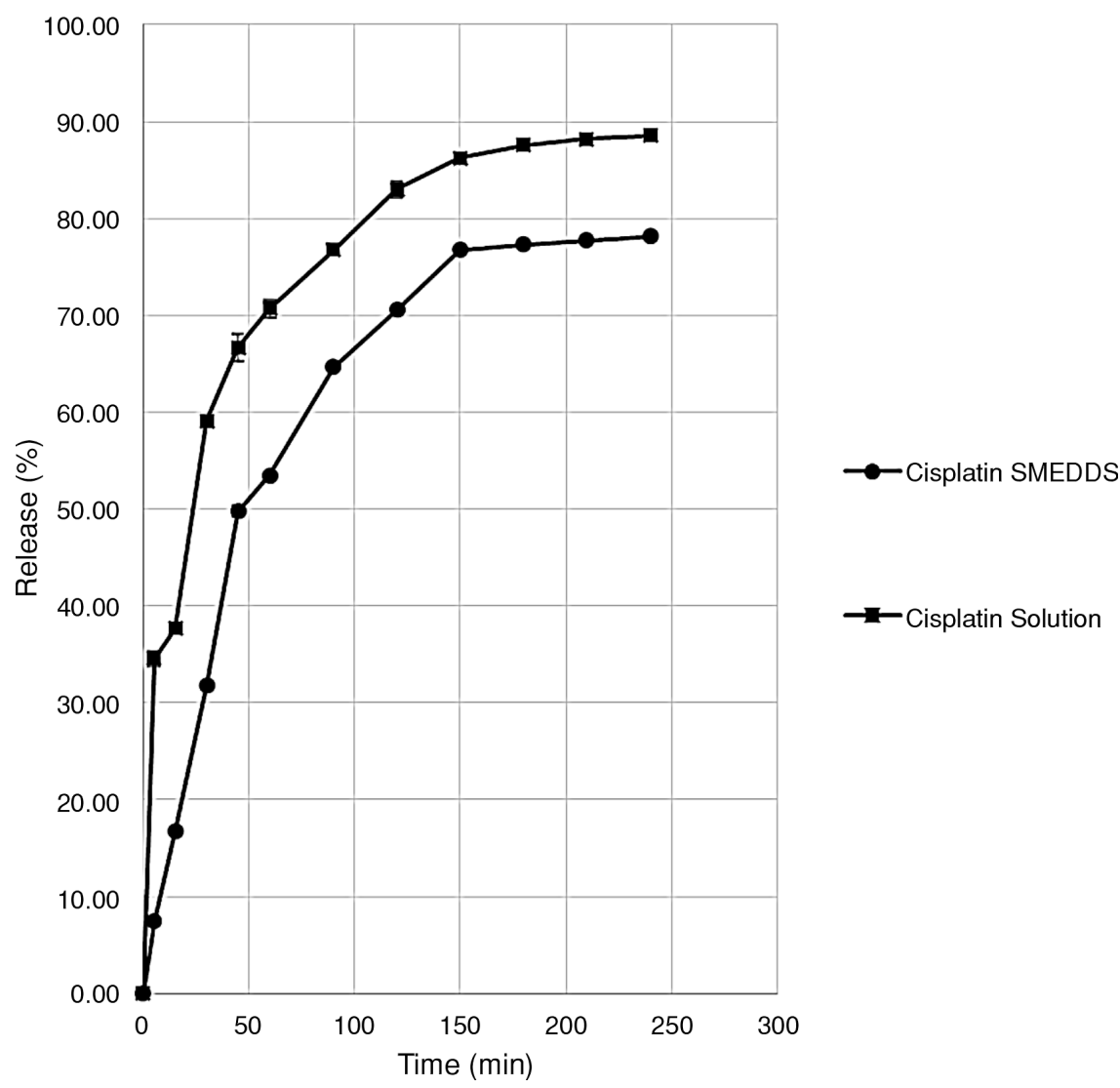

Figure 4. Time versus release \% graph of Cisplatin SMEDDS and Cisplatin solution.

Table 4. Dispersion stability of Cisplatin SMEDDS at 0-24 h.

\begin{tabular}{|c|c|c|c|}
\hline 0 hour & Droplet size $(\mathrm{nm})$ & Polydispersity & Zeta potential \\
\hline $1: 10$ (water) & $25 \pm 4.8$ & $0.370 \pm 0.029$ & $-0.110 \pm 0.034$ \\
\hline $1: 100$ (water) & $25 \pm 5.6$ & $0.319 \pm 0.013$ & $-0.018 \pm 0.001$ \\
\hline $1: 250$ (water) & $28 \pm 6.3$ & $0.420 \pm 0.024$ & $-0.062 \pm 0.005$ \\
\hline $1: 500$ (water) & $34 \pm 8.9$ & $0.387 \pm 0.007$ & $-0.021 \pm 0.002$ \\
\hline $1: 10(0.1 \mathrm{~N}, \mathrm{pH} 6.8$ PBS $)$ & $24 \pm 4.8$ & $0.361 \pm 0.015$ & $-0.267 \pm 0.064$ \\
\hline $1: 100(0.1 \mathrm{~N}, \mathrm{pH} 6.8$ PBS $)$ & $20 \pm 5.5$ & $0.221 \pm 0.002$ & $-0.391 \pm 0.088$ \\
\hline $1: 250(0.1 \mathrm{~N}, \mathrm{pH} 6.8 \mathrm{PBS})$ & $24 \pm 5.9$ & $0.381 \pm 0.038$ & $-0.654 \pm 0.081$ \\
\hline $1: 500(0.1 \mathrm{~N}, \mathrm{pH} 6.8)$ & $27 \pm 6.3$ & $0.322 \pm 0.026$ & $-0.981 \pm 0.154$ \\
\hline $24 \mathrm{~h}$ & Droplet size $(\mathrm{nm})$ & Polydispersity & Zeta potential \\
\hline $1: 10($ water$)$ & $28 \pm 3.7$ & $0.398 \pm 0.014$ & $-0.078 \pm 0.012$ \\
\hline $1: 100($ water $)$ & $19 \pm 7.8$ & $0.060 \pm 0.011$ & $-0.064 \pm 0.005$ \\
\hline $1: 250($ water $)$ & $21 \pm 6.7$ & $0.161 \pm 0.005$ & $-0.054 \pm 0.004$ \\
\hline $1: 500($ water$)$ & $22 \pm 6.6$ & $0.316 \pm 0.014$ & $-0.087 \pm 0.008$ \\
\hline $1: 10(0.1 \mathrm{~N}, \mathrm{pH} 6.8$ PBS $)$ & $24 \pm 5.1$ & $0.395 \pm 0.025$ & $-0.242 \pm 0.019$ \\
\hline $1: 100(0.1 \mathrm{~N}, \mathrm{pH} 6.8$ PBS $)$ & $19 \pm 6.4$ & $0.085 \pm 0.023$ & $-0.644 \pm 0.101$ \\
\hline $1: 250(0.1 \mathrm{~N}, \mathrm{pH} 6.8$ PBS $)$ & $20 \pm 4.8$ & $0.218 \pm 0.012$ & $-0.872 \pm 0.185$ \\
\hline $1: 500(0.1 \mathrm{~N}, \mathrm{pH} 6.8)$ & $20 \pm 6$ & $0.137 \pm 0.033$ & $-0.531 \pm 0.078$ \\
\hline
\end{tabular}


be interpreted as the excess of ions in phosphate buffer solution. Less than 0.3 PDI value indicates that droplet size is homogeneous for all kind of dilution ratios. Narrow PDI values show the homogeneity of droplet size distribution in this SMEDDS formulation. The droplet size distribution of Cisplatin SMEDDS (diluted with $1: 10$ water in $0 \mathrm{~h}$ ) was given in Figure 3. The zeta potential value of Cisplatin loaded SMEDDS which was diluted with the ratio of $1: 10$ by water was measured as $-0.127 \pm 0.015 \mathrm{mV}$. The zeta potential value of Cisplatin loaded SMEDDS which was diluted with the ratio of $1: 10$ by simulated intestinal fluid was measured as $-0.224 \pm$ $0.035 \mathrm{mV}$. In optimum formulations, the constancy of zeta potential value indicates that the system is stabilized. Due to the non-ionic surfactants, zeta potential values of diluted mediums were measured almost zero.

The refractive index of Cisplatin loaded SMEDDS formulation was measured as $1.471 \pm 0.001$. The formulation was found clear visually and the refractive index value verified this information. The $\mathrm{pH}$ value of Cisplatin loaded SMEDDS (dilution ratio $1: 10$ water) was $5.84 \pm 0.09$. $\mathrm{pH}$ value of Cisplatin loaded SMEDDS (dilution ratio $1: 10 \mathrm{pH} 6.8 \mathrm{PBS}$ ) was $6.51 \pm 0.14$. Viscosity of Cisplatin loaded SMEDDS formulation was $284 \mathrm{mPa}$. Considering these results, optimum SMEDDS formulation was developed successfully.

Dispersion stability values of Cisplatin SMEDDS were shown in Table 4. According to the results significant changes were not observed for droplet

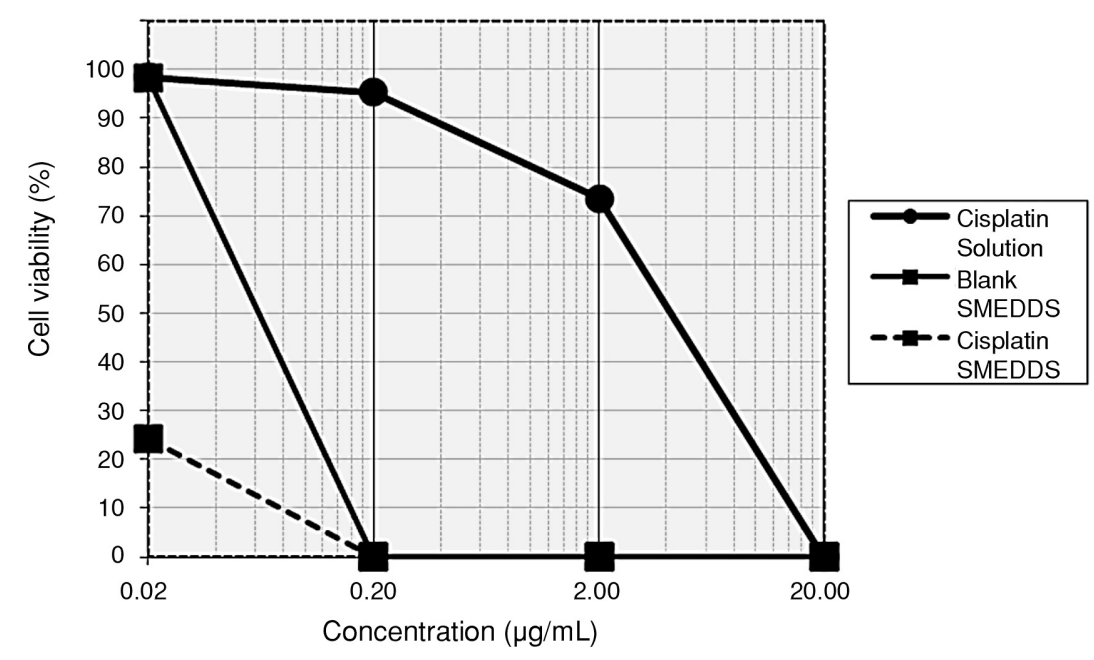

Figure 5. Cell viability of A2780 cells (24 h).

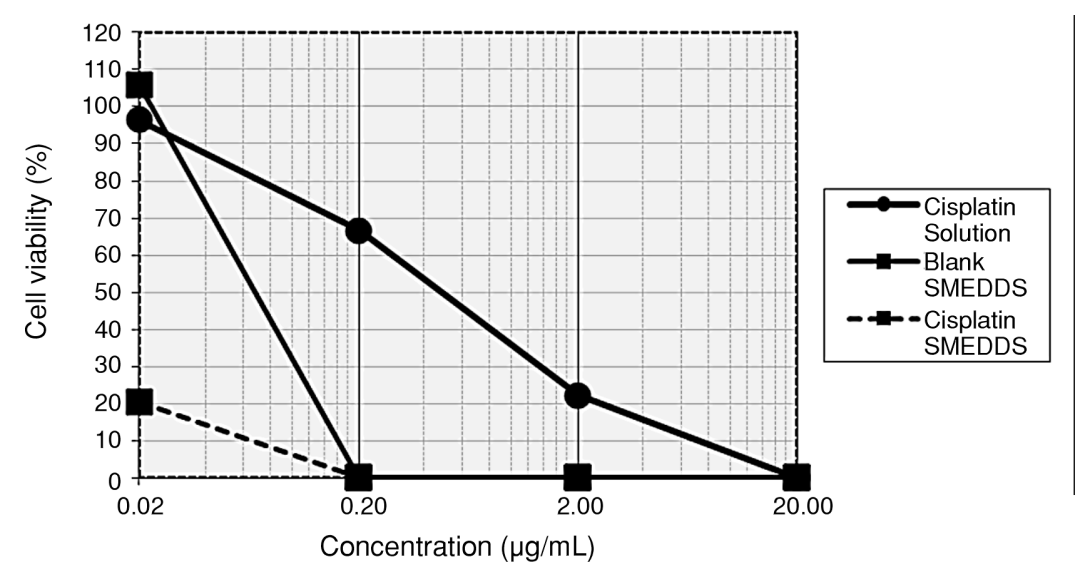

Figure 6. Cell viability of A2780 cells (48 h). 
size, polydispersity and zeta potential values $(\mathrm{p}=$ $0.05)$. Measurements were performed, mean and standard deviation values were calculated $(n=3)$.

In a study, Ujhelyi et al. developed topical SMEDDS formulations containing antitumor agents (bleomycin, cisplatin and ifosfamide). The droplet size of the optimum composition was measured as $73.28 \pm 0.95 \mathrm{~nm}$ and zeta potential was measured as $-6.55 \pm 0.99 \mathrm{mV}$. According to this study, when the droplet sizes are compared with our study, the droplet size of the optimum composition has a similar value with Cisplatin loaded SMEDDS which was diluted with a ratio of $1: 10$ by $0.1 \mathrm{~N} \mathrm{pH}$ 6.8 PBS. However, there was a significant difference between the zeta potential values of the formulations (43).

In another study, (6)-Gingerol-SMEDDS formulation was characterized according to its droplet size, polydispersity index and zeta potential. In this study, similar droplet size and polydispersity index were measured $(73.06 \pm 0.49 \mathrm{~nm}$ and $0.32 \pm 0.02$ respectively), but zeta potential was measured as $2.45 \pm 0.41$ (44).

\section{In vitro release studies of Cisplatin loaded SMEDDS formulation}

Figure 4 shows in vitro release graph of Cisplatin loaded SMEDDS formulation and Cisplatin solution with a concentration of $2 \mathrm{mg} / \mathrm{mL}$. As it can be seen in Figure 4, 78.17\% of Cisplatin was released from Cisplatin SMEDDS formulation and $88.54 \%$ of Cisplatin was released from Cisplatin solutions. According to the results; both Cisplatin SMEDDS and Cisplatin solution showed the Langenbucher model release profile. The maximum coefficient of determination value $\left(\mathrm{r}^{2}\right)$ was calculated in the Langenbucher model which was 0.9533 for Cisplatin SMEDDS and 0.9780 for the Cisplatin solution. The maximum $\mathrm{r}^{2}$ value shows the most suitable release kinetic model for the formulation.

In a study of Hintzen et al. Leuprorelin containing SMEDDS was developed and in vitro release studies were performed using dialysis tubes (MWCO $10.000 \mathrm{Da}$ ) in phosphate buffer pH 6.8. The system was incubated in a beaker under stirring, and the amount of leuprorelin in the outer water phase was quantified. Leuprorelin release profiles from an aqueous leuprolide acetate solution and Leu-SMEDDS emulsified in phosphate buffer $\mathrm{pH}$ 6.8 were found similar. The release of leuproline $\%$ was detected a little bit higher for the euprolide acetate solution. Difference factor (f1) and similarity factor values were calculated as 38.714 and 35.983 respectively. In our study, the release profile of Cisplatin solution and Cisplatin SMEDDS were statistically different from each other $(p<0.05)$ (45).

\section{Cytotoxicity studies of Cisplatin SMEDDS}

After the characterization and in vitro release studies, cytotoxicity studies were performed to evaluate the antitumoral activity of Cisplatin SMEDDS on A2780 cell line. Figure 5 and 6 shows the cell viability of A2780 cells in $24 \mathrm{~h}$ and $48 \mathrm{~h}$ respectively for Cisplatin solution, blank SMEDDS and Cisplatin SMEDDS.

According to the results at the end of $48 \mathrm{~h}$, all of the samples showed decreasing vitality with increasing concentration. Cisplatin solution has the least cytotoxic effect, it showed $66.63 \%$ vitality with a concentration of $0.2 \mu \mathrm{g} / \mathrm{mL}$. When a concentration was increased to $2 \mu \mathrm{g} / \mathrm{mL}$, vitality decreased to $22.2 \%$. All of the cells died at $20 \mu \mathrm{g} / \mathrm{mL}$. Blank SMEDDS performed more cytotoxic effect than Cisplatin Solution in the same dilution ratios. Maximum vitality was detected at $0.02 \mu \mathrm{g} / \mathrm{mL}$ and the vitality decreased until $0.2 \mu \mathrm{g} / \mathrm{mL}$. All of the cells died at $20 \mu \mathrm{g} / \mathrm{mL}$. Cisplatin SMEDDS performed the maximum cytotoxic effect. It showed $20.26 \%$ vitality at $0.02 \mu \mathrm{g} / \mathrm{mL}$ and all of the cells died until $0.2 \mu \mathrm{g} / \mathrm{mL}$.

Bao et al. performed a cell viability assay to determine the cell viability of cisplatin in A2780 and A2780cp cell lines. After $24 \mathrm{~h}$, cell viability of A2780 cell line which was treated with cisplatin was around $\sim 70 \%$ for $5 \mu \mathrm{g} / \mathrm{mL}$ concentration, $\sim 30 \%$ for $10 \mu \mathrm{g} / \mathrm{mL}$. Almost all of the cells died for a concentration of $20 \mu \mathrm{g} / \mathrm{mL}$. Similar cell viability percentages were obtained in our study for $24 \mathrm{~h}$ A2780 cell viability study of Cisplatin (46).

In a study of W. Wu et al. cell viability assay was performed with a Cell Counting Kit-8 (CCK-8) in order to determine the inhibition $\%$ of Cisplatin in A2780 cells. According to the results, inhibition \% was detected as $\sim 40 \%$ for $3 \mu \mathrm{g} / \mathrm{mL}$ and $\sim 60 \%$ for $8 \mu \mathrm{g} / \mathrm{mL}$ concentration of cisplatin. Almost all of the cells died for $100 \mu \mathrm{g} / \mathrm{mL}$ concentration of Cisplatin (47).

\section{CONCLUSION}

In vitro release tests demonstrated that Cisplatin SMEDDS formulation has an enhanced release profile. Cell viability studies showed that Cisplatin SMEDDS is more effective towards A2780 cells when compared with the Cisplatin solution. Also, this formulation is suitable if lymphatic targeting is required. It is suggested that Cisplatin SMEDDS formulation could be administered to patients in hard gelatin capsules via oral 
route with measured doses in order to provide lymphatic targeting. In conclusion, Cisplatin SMEDDS is an advantageous formulation for the treatment of ovarian cancer with its antitumoral activity. This formulation could be a promising alternative due to its fewer side effects and enhanced lymphatic targeting.

\section{Conflict of interests}

The authors declare no conflict of interest.

\section{REFERENCES}

1. Reid B.M., Permuth J.B., Sellers T.A.: Can. Biol. Med. 14, 9 (2017).

2. https://www.cancer.org/cancer/ovarian-cancer/about/key-statistics.html/ (accessed on 03.04.2018).

3. Chornokur G., Amankwah E.K., Schildkraut J.M., Phelan C.M.: Gynecol. Oncol. 129, 258 (2013).

4. http://www.who.int/cancer/resources/keyfacts/ en/ (accessed on 03.04.2018).

5. Webb P.M., Jordan S.J.: Best Prac. Res. Clin. Obstet. Gynaecol. 41, 3 (2017).

6. Daum H., Peretz T., Laufer N.: Fertil. Steril. 109, 33 (2018).

7. https://www.cancer.org/cancer/ovarian-cancer/causes-risks-prevention/risk-factors.html/ (accessed on 04.04.2018).

8. Saed G.M., Diamond M.P., Fletcher N.M.: Gynecol. Oncol. 145, 595 (2017).

9. Crane E.K., Brown J.: Gynecol. Oncol. 149, 598 (2018).

10. Liu D., Zhang L., Indima N., Peng K., Li Q., et al.: Eur. J. Radiol. 90, 225 (2017).

11. Garavaglia E., Sigismondi C., Ferrari S., Candiani M.: Med. Hyp. 110, 80 (2018).

12. Ataseven B., Chiva L.M., Harter P., GonzalezMartin A., du Bois A.: Gynaecol. Oncol. 142, 597 (2016).

13. Ottevanger P.B.: Semin Cancer. Biol. 44, 67 (2017).

14. Schultz H.B., Thomas N., Rao S., Prestidge C.A.: Eur. J. Pharm. Biopharm. 125, 13 (2018).

15. Bibi H.A., Holm R., Bauer-Brandl A.: Eur. J. Pharm. Biopharm. 117, 300 (2017).

16. Beloqui A., del Pozo-Rodriguez A., Isla A., Rodriguez-Gascon A., Solinis M.A.: J. Drug Deliv. Sci. Technol. 42, 144 (2017).

17. Kalepu S., Manthina M., Padavala V.: Acta Pharm. Sin. B 3, 361 (2013).

18. Katla V.M., Veerabrahma K.: J. Drug Deliv. Sci. Technol. 35, 190 (2016).
19. Vasconcelos T., Marques S., Sarmento B.: Eur. J. Pharm. Biopharm. 123, 1 (2018).

20. Yeom D.W., Son H.Y., Kim J.H., Kim S.R., Lee S.G., et al.: Int. J. Pharm. 506, 302 (2016).

21. http://kocakfarma.com/urun-aciklama.aspx? bolumSeo=kisabilgi\&id=38\&lang=tr/ (accessed on 03.04.2018).

22. Moffat A.C., Osselton M.D.: Clarke's Analysis of Drugs and Poisons. 4th ed., Widdop B. editors., pp.1114-1115, Pharmaceutical Press, London 2011.

23. Sweetman S.C. (Eds.): Martindale: The Complete Drug Reference. 38th ed., pp. 698700, Pharmaceutical Press, London 2009.

24. Tao Y., Rezai K., Brain E., Etessami A., Lusinchi A., et al.: Radioter. Oncol. 98, 42 (2011).

25. Vishwakarma N., Jain A., Sharma R., Mody N., Vyas S., Vyas S. P.: AAPS PharmSciTech. 20, 83 (2019).

26. Dokania S., Joshi A.K.: Drug Deliv. 22, 675 (2015).

27. Silva A.C., Santos D., Ferreira D., Lopes C.M.: Curr. Med. Chem. 19, 4495 (2102).

28. Seok S.H., Lee S.A., Park E.S.: J. Drug Deliv. Sci. Technol. 43, 409 (2018).

29. Ege M.A., Karasulu H.Y., Guneri T.: 4th Int. Post-grad. Res. Sym. Pharm. Istanbul, Turkey. 46, 36 (2004).

30. Martinez-Martinez F., Gutierrez-Becerra A., Casillas N., Gradzielski M., Escalante J.I., Barcena-Soto M.: Coll. Surf. A 541, 10 (2018).

31. Acharya D.P., Hartley P.G.: Curr. Opin. Colloid. Interface Sci. 17, 274 (2012).

32. Sindhu P., Kumar S., Iqbal B., Ali J., Baboota S.: J. Psychiatr. Res. 99, 83 (2018).

33. International Conference on Harmonization Guidelines, Validation of Analytical Procedures: Text and Methodology Q2(R1), 1994.

34. Ege M.A., Karasulu H.Y., Karasulu E., Ertan G.: in Proceedings of the 4th Central European Symposium on Pharmaceutical Technology, Vienna, Sci. Pharm. (Suppl. 1) 69, 127 (2001).

35. Siepmann J., Siepmann F.: Int. J. Pharm.: 453, 12 (2013).

36. Samper K.G., Marker S.C., Bayon P., MacMillan S.N., Keresztes I.: J. Inorg. Biochem. 174, 102 (2017).

37. Sirota R., Gibson D., Kohen R.: Redox Biol. 11, 170 (2017).

38. Sweetman S.C. Eds.: Martindale. The Complete Drug Reference. 38th ed. Isopropyl myristate, p. 2029, Pharmaceutical Press, London 2009. 
39. https://pharmaceutical.basf.com/en/DrugFormulation/Kolliphor-EL.html/ (accessed on 09.04.2018).

40. Sweetman S.C. Eds.: Martindale. The Complete Drug Reference. 38th ed. Propylene Glycol, p. 2374, Pharmaceutical Press, London 2009.

41. Omari-Siaw E., Zhu Y., Wang H., Peng W., Firempong C.K., et al.: Eur. J. Pharm. Sci. 85, 112 (2016).

42. Wang H., Li Q., Deng W., Omari-Siaw E., Wang Q., et al.: Drug Dev. Res. 76, 82 (2015).

43. Ujhelyi Z., Kalantari A., Vecsernyes M., Roka E., Fenyvesi F., et al.: Molecules 20, 13226 (2015).
44. Xu Y., Wang Q., Feng Y., Firempong C.K., Zhu Y., et al.: J. Funct. Foods 27, 703 (2016).

45. Hintzen F., Perera G., Hauptstein S., Müller C., Laffleur F., Bernkop-Schnürch A.: Int. J. Pharm. 472, 20 (2014).

46. Bao L., Jaramillo M.C., Zhang Z., Zheng Y., Yao M., et al.: Mol. Med. Rep. 11, 91 (2015).

47. Wu W., Fan L., Bao Z., Zhang Y., Peng Y., et al.: Biochem. Biophys. Res. Commun. 487, 292 (2017).

(C) 2020 by Polish Pharmaceutical Society. This is an open access article under the CC BY NC license (c) (i) () (http://creativecommons.org/licenses/BY/4.0/). 